\title{
New Animal Data on Osmotic and Hypovolemic Thirst
}

\author{
Daniel G. Bichet ${ }^{\mathrm{a}, \mathrm{b}}$ \\ aDepartment of Medicine, Pharmacology and Physiology, University of Montreal Montréal, Montreal, QC, Canada;

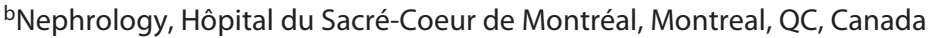

\section{Keywords}

Osmotic thirst $\cdot$ Hypovolemic thirst $\cdot$ Subfornical organ .

Organum vasculosum of the lamina terminalis . Taste

receptors

\begin{abstract}
Introduction: The group of Yuki Oka, working at Caltech, recently discovered unique populations of neurons in the mouse brain that separately drive osmotic thirst and hypovolemic thirst [1]. After eating salty chips, the concentration of salts and minerals in blood becomes elevated which induces a state called osmotic thirst. On the other hand, after exercising and losing water and some electrolytes, a different thirst called hypovolemic thirst occurs since extracellular fluid volume is reduced. Two brain regions have already been defined to be important in drinking behaviors in animals, the subfornical organ and the organum vasculosum of the lamina terminalis. Methods: With a technique called single-cell RNA-seq, single cells were found to be involved in specific behavior states, that is, either drinking pure water and avoiding salty water, osmotic thirst, or, appetite for mineral-rich liquids for hypovolemic thirst (Fig. 1). Discussion/ Conclusion: Thirst is therefore a multimodal, many ways, 2 or more, of doing things, sensation, activated by 2 different stimuli, osmotic and hypovolemic. Multimodal means having, or using, a variety of modes, or methods to do some-
\end{abstract}

thing. Multimodal teaching is a style in which students learn material through a number of different sensory modalities. For example, a teacher will create a lesson in which students learn through auditory and visual methods. For thirst, the 2 circumventricular sensory group of neurons, that is, the subfornical organ and organum vasculosum of the lamina terminalis, are able to perceive 2 modes of thirst. Other peripheral sensory systems are also characterized by multimodal sensations like taste and olfaction. The fungiform papilla of the anterior tongue involved in water and salt tasting is also described as a complex multimodal sensory organ for taste, tactile, and temperature modalities [2]. The instantaneous and simultaneous sensations of taste, touch, and temperature when solid or liquid stimuli contact the tongue tip are necessary for eating and drinking. Oka and his team [3] also found that the tongue has a taste for water: applying deionized water to mouse tongues caused specific taste nerves to fire owing to a change in the $\mathrm{pH}$ of the saliva as it was diluted by the water. Water is detected only by acid-sensing taste receptor cells (type III cells). The appetitive sodium responses are mediated through the sodium-selective ENaC pathway (type III cells), whereas the rejection of high salt results from the recruitment of the sour- and bitter-taste-sensing pathways (type II cells) [4]. It is therefore inferred that our brain senses internal states by using similar strategies.

C 2022 The Author(s).

Published by S. Karger AG, Basel
C 2022 The Author(s).

Published by S. Karger AG, Basel

This article is licensed under the Creative Commons Attribution 4.0 International License (CC BY) (http://www.karger.com/Services/ OpenAccessLicense). Usage, derivative works and distribution are permitted provided that proper credit is given to the author and the original publisher.
Correspondence to:

Daniel G. Bichet, daniel.bichet@umontreal.ca 
Fig. 1. Optogenetic activation of RXFP1 (relaxin/insulin-like family peptide receptor 1) neurons drive selective drinking of pure water (left). Conversely, stimulation of prodynorphin neurons drives consumption of both water and hyperosmotic salt solution (right) Modified and redrawn from [1].
Optogenetic activation of osmotic stress-sensitive neurons in the SFO or OVLT
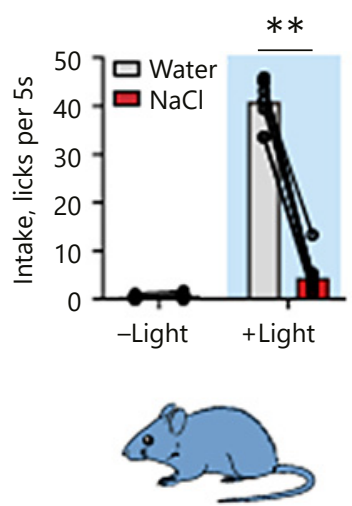

Active neurons

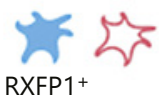

Behavioural output

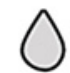

Pure water
Optogenetic activation of hypovolaemic stress-sensitive neurons in the SFO or OVLT
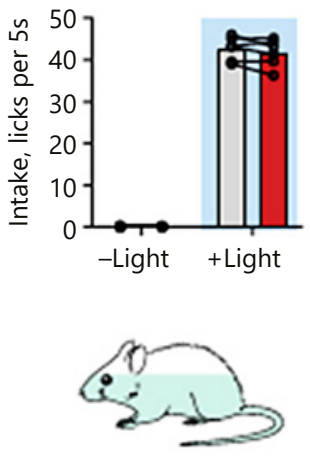

Active neurons

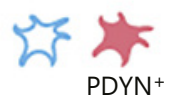

Behavioural output

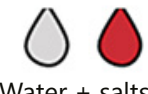

\section{Statement of Ethics}

This work is based on previously published data and therefore does not require ethical approval.

\section{Conflict of Interest Statement}

The author has no conflicts of interest to declare.

\section{Funding Sources}

This study was supported by Research Center, Hôpital du Sacré-Cœur de Montréal.

\section{Data Availability Statement}

The data referred to in this abstract can be found in reference [1].

\section{References}

1 Pool AH, Wang T, Stafford DA, Chance RK, Lee S, Ngai J, et al. The cellular basis of distinct thirst modalities. Nature. 2020;588(7836): $112-7$.

2 Mistretta CM, Bradley RM. The fungiform papilla is a complex, multimodal, oral sensory organ. Curr Opin Physiol. 2021;20:165-73.
3 Zocchi D, Wennemuth G, Oka Y. The cellular mechanism for water detection in the mammalian taste system. Nat Neurosci. 2017; 20(7):927-33.

4 Bichet DG. Regulation of thirst and vasopressin release. Annu Rev Physiol. 2019;81:359_ 73. 